\title{
Two contrasted cases of complete heart block observed over many years
}

\author{
G. H. Jennings \\ From Edgware General Hospital, Edgware, Middlesex
}

\begin{abstract}
Two contrasted cases of complete heart block, one of rheumatic aetiology, the other congenital, have been observed over nearly 30 years. Despite severe associated cardiac defects in the congenital case, both have led active lives. Evidence is adduced that the prognosis in these two forms of complete block may be relatively good. The rarity of complete rheumatic heart block is noted and also its association with otherwise mild rheumatic cardiac sequelae. Complete heart block in the case described evolved from rheumatic partial heart block and after nearly 30 years partial heart block is still present.
\end{abstract}

That complete heart block is a relatively rare heart condition, especially in younger subjects, has been made clear by a number of studies. Out of 14,000 records over 19 years in the Electrocardiograph Department at the Massachusetts General Hospital, only 72 cases were found and 47 of these were due to coronary artery disease (Graybiel and White, 1936). At Brooklyn over a I0-year period I4 cases below the age of 40 years were seen (Crawford and Di Gregorio, 1947); Sprague and White (1927), reviewing cases below 30 years of age seen at the Massachusetts General Hospital during the previous 22 years, found 9 cases of complete heart block and 2 of partial high grade block.

The even greater rarity of congenital and rheumatic heart block is emphasized by the detailed analysis of these figures. Only 4 of Graybiel and White's 72 cases were certainly of congenital type, 2 in the series of Crawford and Di Gregorio, and $I$ in Sprague and White's series. Acceptable cases of rheumatic aetiology respectively number 3,5 , and 2 (possibly 4) in these three series.

White comments on the difficulty of recognizing the aetiology of the rheumatic heart block when seen years after its establishment, particularly since it may ultimately be the only residual physical sign of the carditis. - Degrees of block recognized during the active phase of rheumatic fever are usually minor prolongations of the PR interval; such findings are usually transient (Cobbs, 1966; Wood, 1968). Cobbs who found PR prolongation in about 20 per cent of his active rheu-

Received Is May 1970. matic cases regarded complete block in this condition as very rare. Histological evidence (Gross and Fried, 1936) showed active inflammation in the bundle of $\mathrm{His}$ and septum fibrosum in 40 out of 60 cases dying in acute rheumatism, but not present in inactive rheumatic cases. But complete heart block may persist long after rheumatic activity has ceased, as mentioned by White (I95I) and as in the case to be described below. In contrast with this case, a congenital heart block, suspected in utero, is described. These two cases have now been observed for nearly 30 years.

\section{Case I: Rheumatic complete heart block}

A small boy was admitted to hospital (aged 3 years) in May 1942 with history of two weeks' malaise following a sore throat. His symptoms had included attacks of dyspnoea, delirium, and sweating. One week before admission he had had pains in the legs for one day and on the day before admission he had had pains in the arms for one day. His previous history included many sore throats. Otherwise he had been well and active.

On admission he appeared comfortable and well nourished. Colour was good and tongue clear. Tonsils, though large and fleshy, showed no active inflammation and cervical glands were not enlarged. His joints were not swollen. Temperature $36.7^{\circ} \mathrm{C}$. at admission rose to $38.3^{\circ} \mathrm{C}$. on the second day but quickly settled to normal level and so remained throughout nearly the whole of his period of rest and observation. Pulse rate 64 at admission rose to 120 with the rise of temperature and then gradually settled to 80 a week later and afterwards was usually between 40 and 50 a minute. At admission the heart showed slight enlargement to the left with a blowing systolic murmur in all areas. Six days later a short early 
FIG. I Sequence of electrocardiographic changes in Case I. (a) $2: 1$ block shown in the first and third months after rheumatic fever; (b) complete block persisting from ninth month to two years after illness; (c) 2:I block in ninth and tenth years. (Dates shown to left of tracings.)

diastolic murmur was also noted and this was clearly present during the next month, after which it was gradually lost. The apical systolic murmur persisted till his discharge to a Rheumatic Heart Home in September and was accentuated during an exacerbation of tonsillitis in August $\left(38.5^{\circ} \mathrm{C}\right.$.). At this time the pulse rate rose briefly to 84 , otherwise the bradycardia was as stated. Erythrocyte sedimentation rate, $100 \mathrm{~mm}$., 5 days after admission (Westergren) had fallen to ro $\mathrm{mm}$. a month later when the haemoglobin level was 92 per cent. After admission he had no rheumatic symptoms and no specific therapy was given.

He was followed up regularly for the next to years, when he moved to Kent (1952), and was always found to be well, though a systolic murmur persisted at the apex and there was constant bradycardia. His unhealthy tonsils were removed 3 years after his admission. Otherwise he enjoyed uninterrupted schooling, despite developing a

1 pollen sensitivity in 194I which caused hay fever and summer asthma.

The electrocardiograms taken during this time as can be seen (Fig. I) showed a change from 2:I

- block during the first months after the illness to complete block during the period from the 9th to 25th months (Fig. Ia and b). During 1949 to 1952, from 8 to ro years after the onset, the block had

- reverted to 2:I (Fig. Ic).

He reported again for examination at the end of August 1969, over 27 years from his rheumatic attack, looking well and with no history of symptoms other than hay fever and asthma since 1952. Though his work in the docks as meat sur-

+ veyor necessitated humping heavy carcasses he was only dyspnoeic at the times of asthma.

Examination (August 1969) Well-built man of - good colour. No evident cardiac enlargement, though a short apical systolic murmur persisted and occasional short slurred diastolic sounds with dropped beats were noted from time to time; - pulmonary second sound not much accentuated; no evidence of decompensation; pulse rate 48-60; BP $130 / 80 \mathrm{~mm}$. Hg. Chest $x$-ray showed very slight enlargement of the heart (C/T ratio 14.5 )

FIG. 2 Case I (28.8.69). Varying degree of block. Lead I shows grade I block (PR 0.52 sec.); leads II, III, aVR, aVL, aVF, $V I$, and VI show Wenckebach's phenomenon; in $V_{3}$ this is accentuated, with many dropped beats; in V4-V6 there is again grade I block (PR 0.42 sec.). Poor T waves also suggest old myocardial change.
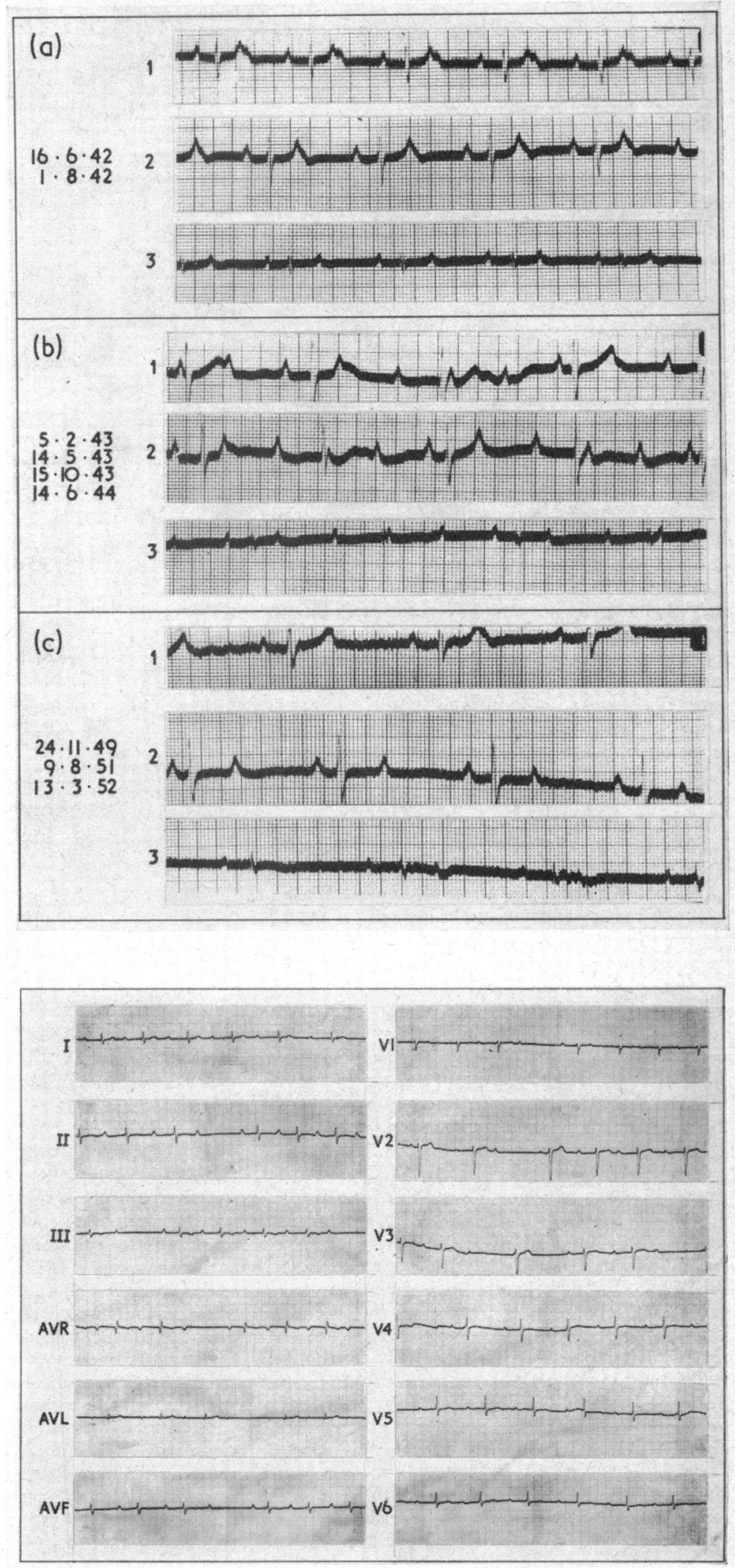
25.5) but no obvious left atrial fullness. Electrocardiogram showed changing degrees of block, sometimes a Wenckebach phenomenon with dropped beats and sometimes grade I block with PR intervals varying between 0.44 and $0.52 \mathrm{sec}$. (Fig. 2).

\section{Case 2: Congenital complete heart block}

The patient's mother, a primigravida at term, was admitted to Bushey Maternity Hospital in March I94I and the foetal heart rate was observed to vary between 40 and 52 beats a minute. After delivery the infant appeared well but showed a persistent heart rate of between 40 and 48 ; no murmurs were audible and the child, taking the breast well, showed a good colour. An electrocardiogram, taken with some difficulty at ro days of age, confirmed, the presence of complete heart block (Fig 3a). The patient, followed from infancy to the present time, remained fairly well but tended to be bronchitic in her early years. Pulse was always slow, 40 to 60 , and murmurs were detected, a systolic murmur at the pulmonary area in August 1943, and by April r945 a clear 'machinery' type systolic and diastolic murmur and thrill characteristic of persistent ductus arteriosus, $\mathrm{BP}$ II5/20 mm. $\mathrm{Hg}$. At this time she was quite well and lively, but her mother had noted that if she cried or was excited her lips became bluish; also a long walk made her tired. Between these dates the heart showed clear evidence of enlargement and $x$-ray in February 1946 showed conspicuous left ventricular enlargement and fullness of the pulmonary conus (Fig. 4a). The left ventricular hypertrophy was marked by a forcible heaving impulse well beyond the midclavicular line on the apical area. She was transferred to the Thoracic Unit at Hillingdon Hospital in May 1947 and in June the ductus was tied by Mr. L. Fatti who also found a double aorta with the anterior arch slightly coarcted at its junction with the main arch (Fig. 5). Pertussis caused cyanosis for a while after the operation and increased prominence of the pulmonary conus was seen subsequently in $x$-ray (Fig. 4 b). In November I949 she was much better, active without dyspnoea and developing well. The pulmonary area diastolic murmur was a little less prominent subsequent to the operation, but a faint systolic thrill and a long systolic murmur persisted at the pulmonary area; an apical systolic murmur also became obvious and has persisted to the present time. In November 1949 the apical impulse was $3.5 \mathrm{~cm}$. outside the mid-clavicular line. BP I40/80 $\mathrm{mm}$. Hg. Complete heart block then and afterwards (Fig. $3 \mathrm{~b}$ and $3 \mathrm{c}$ ). At 12 years she ascended stairs easily and could run 30 yards before she became dyspnoeic. Regular observation showed little change in the heart signs or exercise tolerance. But a gradual diminution of the pulmonary area diastolic murmur (sometimes to absence) and increasing accentuation of pulmonary second sound had been noted. BP I55/70 mm. Hg. Normal slow femoral pulses. She worked in London as a fashion artist on leaving school and she kept very well, apart from occasional shortness of breath

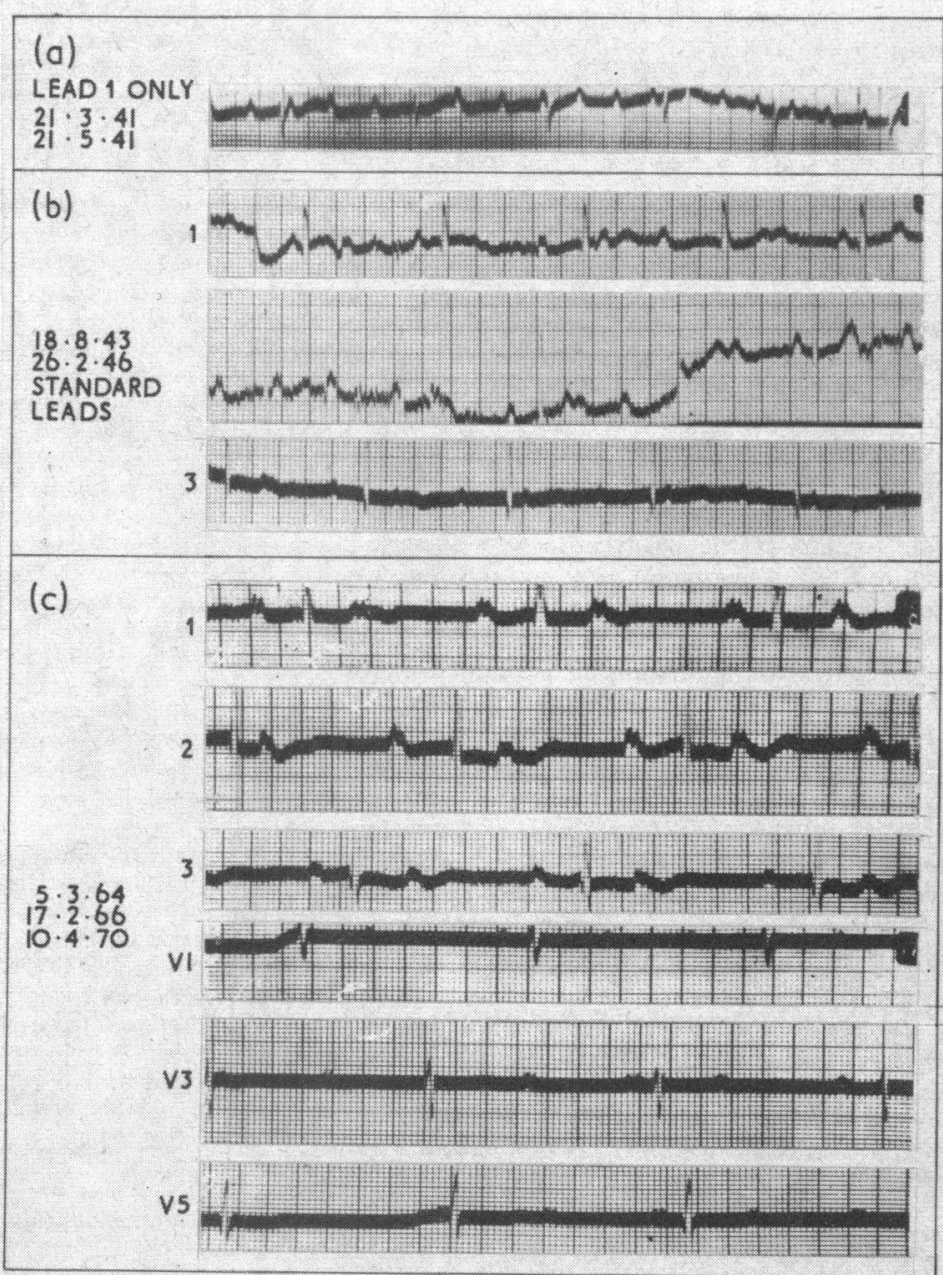

FIG 3 (a), (b), and (c). Electrocardiograms of Case 2 showing persistence of complete heart block over first 29 years of life. Widening of $Q R S$ complexes in latter years.

when rushed and during one period in 1964 when she had occasional weight-like sensations across the chest during a spell of unusual exertion. $X$ rays between 1949 and 1964 showed further dilatation of the pulmonary conus and increase in cardiac transverse diameter due to enlargement of both ventricles; there was obvious pulsation both in the pulmonary conus and in the aortic knuckle; no hilar dance was seen but some pulmonary hyperaemia became evident. She developed fully (weight $56 \mathrm{~kg}$.) and colour was good, apart from a slight tint of cyanosis in her high colour first noticed in 1955. She married at the end of 1964 , ran a three-bedroomed house in Bucks, and continued with part-time work in London. After 4 months she noted increased dyspnoea on stairs, but was not very dyspnoeic or cyanotic when she reported 2 months' pregnant in February 1966. 


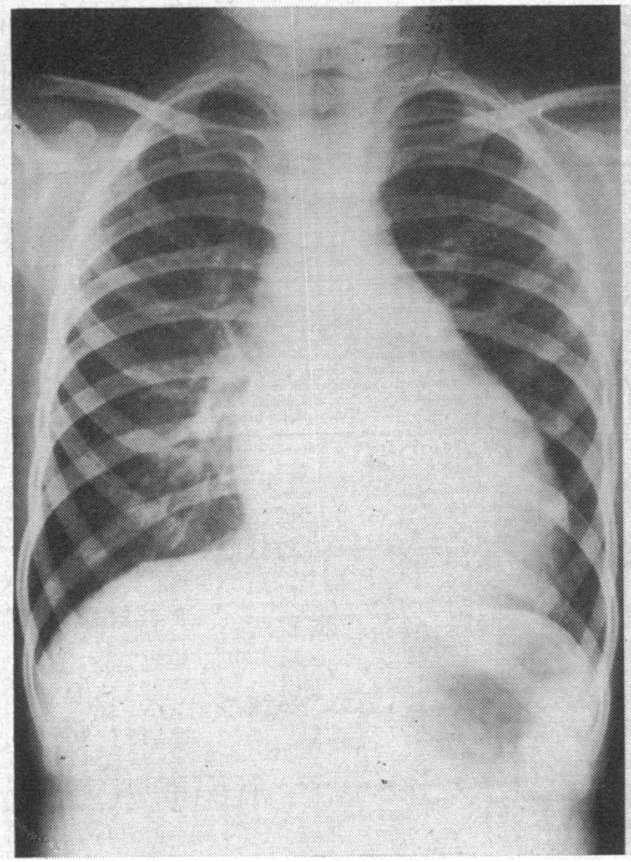

(a)

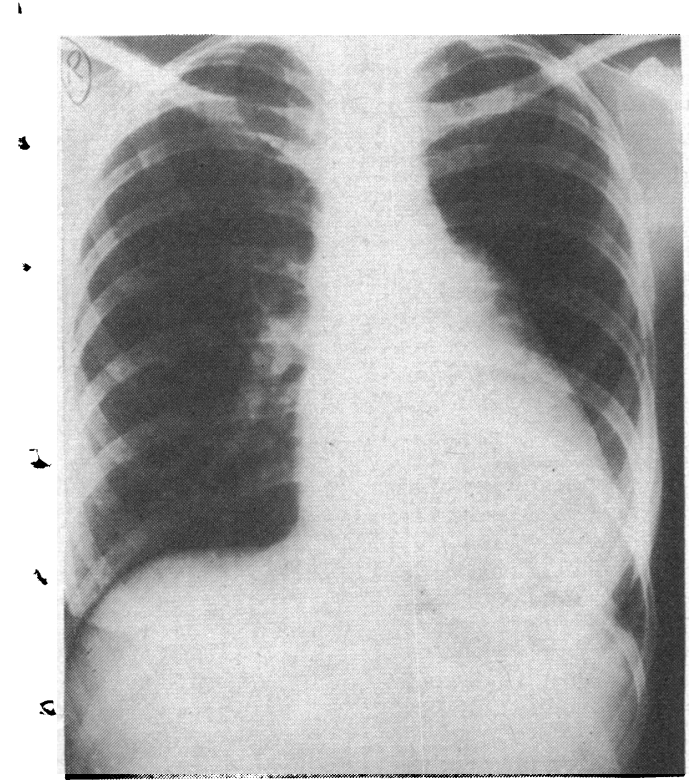

(c)

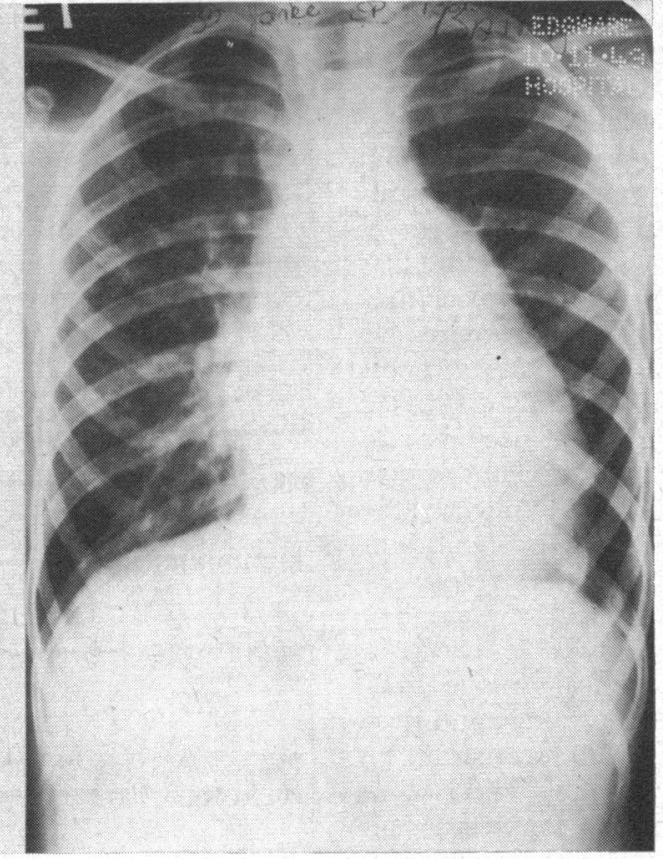

(b)

Heart signs were unchanged and haemoglobin 85 per cent (12.5 g.). Compensation remained good both before and after caesarean section in September by Mr. E. ap. I. Rosser who also had attended her birth in 1941. After delivery of a healthy male child, weight $3270 \mathrm{~g}$., sterilization by cutting and ligating of the tubes was performed. Mother and child continue well to the time of writing at the end of April 1970.

\section{Discussion}

These two patients are described to illustrate the course over many years of contrasted cases of heart block. One, a congenital case, is naturally still in complete block; the other of rheumatic aetiology now shows a lessened degree of block. The relatively benign course of these two cases of complete heart block is emphasized by the histories, the congenital case with severe accompanying cardiac defects passing successfully through a pregnancy; the rheumatic holding down a heavy job in the docks. Complete rheumatic heart block is rare, but as in the interesting case of Campbell (I93I) it may be more transient than in Case I. Maurice Campbell (1970, personal communication) tells me that his case which developed complete heart block in her fourth attack of rheumatic fever, having previously acquired an aortic reflux, survived 39 years after showing complete block, living to the age of 67. Her complete block lasted a week 
and then became partial for 7 months before clearing completely and permanently.

My rheumatic case illustrates the difficulty of correct attribution of heart block to this illness. His initial illness was not severe, and White (1915, 195I) has emphasized that this type of rheumatism can be the precursor of heart block, that heart block may be the first sign of it, and that persistent heart block may be the only ultimate sign of a non-progressive rheumatic carditis. One of the cases in his joint series with Graybiel was only diagnosed as a healed rheumatic carditis at necropsy. In my case, in addition to the history and cardiac signs compatible with rheumatic endocarditis, the lessening degree of block is significant. Examining past series such as those of Sprague and White (1927) and of Campbell and Suzman (1934), it is noticeable that cases with complete block and apical systolic murmurs have been classified as congenital despite histories of sore throats, scarlatina, or even of rheumatism. The latter writers correctly state the three criteria for diagnosing congenital block: (a) no history of significant previous infection; (b) other signs of congenital heart disease; (c) slow pulse observed at an early age.

My second case fulfils all these criteria, the diagnosis being suspected in utero and electrocardiographically confirmed shortly after birth. The successful pregnancy in White's (I95I) case of complete heart block matches the experience of this case. The prognosis in congenital, as in rheumatic, complete heart block may evidently be much better than might be surmised. In Graybiel and White's series of this degree of block, most of those showing decompensation were of ischaemic aetiology.

I am indebted to the Thoracic Unit at Hillingdon Hospital, and particularly to Mr. H. C. Nohl-Oser, for sending me Mr. L. Fatti's diagrams. I am much indebted to Dr. Maurice Campbell for further notes on his case.

\section{References}

Campbell, M. (I93I). Complete and partial heartblock during an attack of rheumatic fever. Lancet, 2, 180.

- , and Suzman, S. S. (1934). Congenital complete heart-block. American Heart fournal, 9, 304.

Cobbs, B. W., Jr. (1966). Clinical recognition and medical management of rheumatic fever and val-

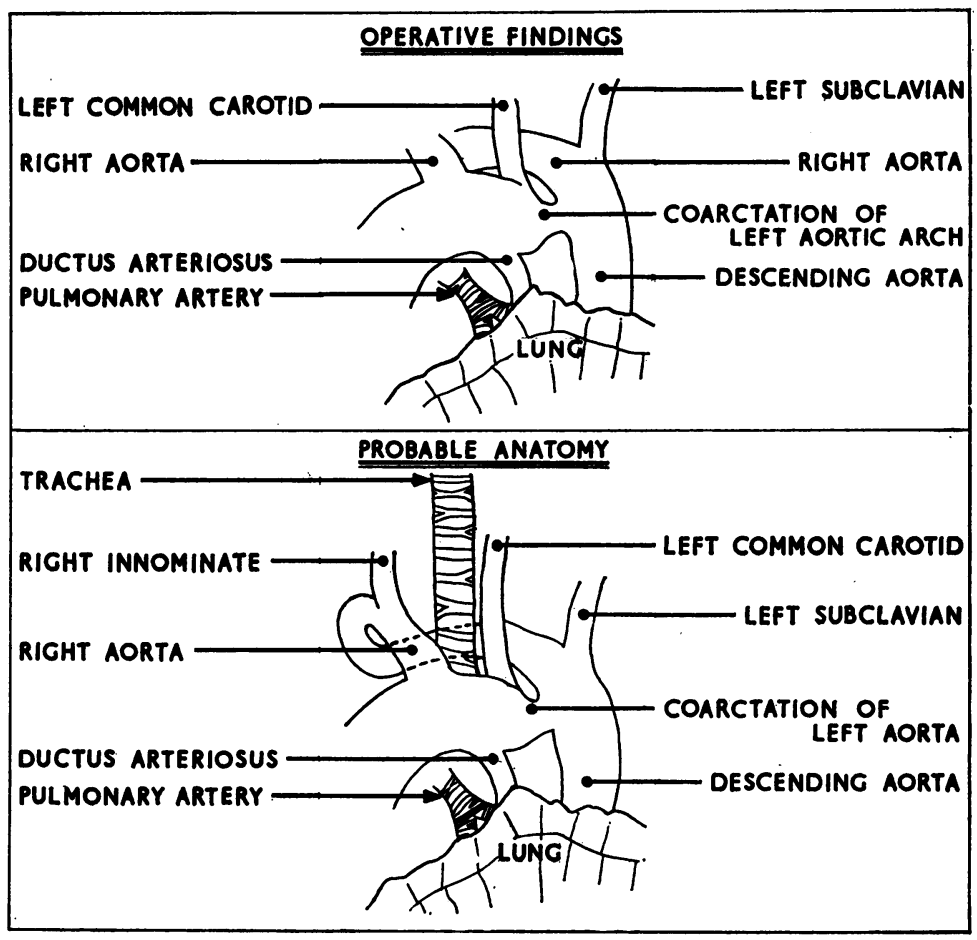

FIG. 5 Sketch made at operation (I0.6.47)

in Case 2 to show the abnormalities of the great vessels and their relation. These include double aorta, with coarctation of the left aorta, and persistent ductus arteriosus.

vular heart disease. In The Heart, p. 519. Ed. by J. W. Hurst and R. B. Logue. McGraw-Hill, New York.

Crawford, J. H., and Di Gregorio, N. J. (1947). Complete heart-block in younger age groups. American Heart fournal, 34, 540.

Graybiel, A., and White, P. D. (1936). Complete auriculo-ventricular dissociation; a clinical study of 72 cases. American fournal of the Medical Sciences, 192, 334.

Gross, L., and Fried, B. M. (1936). Lesions in the auriculoventricular conducting system occurring in rheumatic fever. American fournal of Pathology, 12, 31.

Sprague, H. B., and White, P. D. (1927). High-grade heart-block under the age of thirty. Medical Clinics of North America, 10, 1235.

White, P. D. (1916). Acute heart block occurring as the first sign of rheumatic fever. American fournal of the Medical Sciences, 152, 589.

(1951). Heart Disease, 4th ed. Macmillan, New York.

Wood, P. H. (1968). Diseases of the Heart and Circulation, 3rd ed. Eyre and Spottiswoode, London. 